\title{
Idosos aposentados: representações do cotidiano ${ }^{1}$
}

Maria da Glória Silva e Silva²

\section{Resumo}

No imaginário da sociedade moderna, o trabalho é exaltado e tem caráter de obrigação moral. A aposentadoria e o afastamento deste pode representar uma ruptura identitária, implicando numa reorganização do projeto de vida. Neste processo, surgem novas atividades no cotidiano do idoso em substituição à atividade profissional. O estudo que deu origem a este texto teve como objetivo investigar as representações de idosos aposentados sobre seu cotidiano depois da aposentadoria. Para isso foram analisadas transcrições de entrevistas realizadas com aposentados há pelo menos 5anos, com mais de 60anos, de ambos os sexos, ligados ou não a grupos de convivência, escolhidos de forma intencional, não institucionalizados e residentes na zona urbana de Porto Alegre. Das entrevistas, selecionou-se fragmentos de discurso sobre atividades que desempenham atualmente. Verificou-se que muitas das características de atividades de trabalho são mantidas e valorizadas positivamente pelos idosos ao dimensionarem suas práticas cotidianas, ainda que o trabalho esteja pouco presente em seu cotidiano atual. Por outro lado, a disciplina e a hierarquia são características do mundo do trabalho que às quais os aposentados são avessos, não considerando necessário mantê-las nesta etapa da vida.

Palavras-chave: representação social; aposentadoria; velhice.

\section{Abstract}

In the perception of modern society, work is acclaimed and bears a moral obligation characteristic. Retirement and the fact of being away from work, can represent an identity rupture implying in a reorganization of the individual's life goals. In this process, new activities, replacing the professional ones, come up in the senior's daily life. The survey that gave origin to this paper had as its goal, to investigate the retired seniors' representation of his/her daily life after retirement. For such, the transcripts of the interviews carried out with individuals retired for at least 5years,

\footnotetext{
${ }^{1}$ Trabalho desenvolvido como parte da pesquisa "Identidade e Aposentadoria", de autoria de Maria da Graça C. Jaques, Olga Collinet Heredia, Sergio Antonio Carlos e Sandra Vieira Larratéa. Financiamento FAPERGS/CNPq.

${ }^{2}$ Instituto de Psicologia da UFRGS.
} 
over 60years of age, both sexes, linked or not to peer groups, intently chosen, who were not living in institutions, and living in the urban area of Porto Alegre, were analyzed. Discourse fragments on the activities they currently do were selected from the interviews. It was noted that many of the characteristics of the work activities are maintained and positively valued by the seniors when analyzing their daily practices, even if the work is little present in his/her current daily life. On the other hand, discipline and hierarchy are characteristics of the w ork w orld which the retired individuals oppose to, considering them unnecessary at this stage in life.

Key words: social representation; retirement; old age; seniors.

\section{Introdução}

Estudar a representação social do cotidiano de aposentado entre idosos nesta situação torna-se interessante quando se constata que grande quantidade de tempo livre subitamente surge na vida de quem se aposenta. A passagem de trabalhador para aposentado implica em dispor de oito horas adicionais mais o tempo que era destinado ao transporte e outras ações indiretamente ligadas à vida profissional. Com a aposentadoria, o idoso passa a dedicar-se a novas atividades.

O papel de trabalhador é central na constituição identitária. A saída do mundo do trabalho pode representar ruptura nos referenciais de reconhecimento do eu, tomando-se importante uma reorganização do projeto de vida com fins de personalização. A exaltação do trabalho em nossa sociedade implica numa perspectiva de exclusão social intrínseca à situação de aposentadoria, que é ainda o marco estigmatizante de entrada na velhice. A concepção pelo idoso de suas novas atividades está embebida nestes produtos do imaginário social.

O estudo que deu origem a este texto teve como objetivo identificar os conteúdos simbólicos das representações de idosos aposentados sobre seu cotidiano depois da aposentadoria. Para isso foram analisadas transcrições de entrevistas semiestruturadas que compunham o banco de dados do projeto de pesquisa "Identidade e Aposentadoria” realizado pelo Núcleo de Estudos sobre 
Terceira Idade (NETI). As entrevistas centravam-se nas questões de trabalho, aposentadoria e família, e foram realizadas com aposentados há pelo menos cinco anos, com mais de 60 anos, de ambos os sexos, ligados ou não a grupos de convivência, escolhidos de forma intencional, não institucionalizados e residentes na zona urbana de Porto Alegre. Das entrevistas, selecionou-se os fragmentos de discurso referentes ao sentido atribuído ao cotidiano.

A palavra "cotidiano", de acordo com o Dicionário Brasileiro de Língua Portuguesa (1998), significa "o que sucede ou é praticado habitualmente". O aspecto do cotidiano dos aposentados estudado foi o de suas práticas habituais, de suas atividades diárias, ficando em segundo plano os aspectos do cotidiano que se repetem em função de diversas determinações, que simplesmente "sucedem", não ligados diretamente à ação dos aposentados sobre o mundo.

A experiência de viver a aposentadoria pela qual tantos passam é significada de diferentes formas pelos indivíduos, de acordo com determinações culturais, com a história de vida dos sujeitos e com seus potenciais criativos na relação com o objetomundo e com os outros.

Kessler (1998, p. 17) aponta que para Schutz (apud Minayo, 1995, p. 96), as experiências podem ser comuns a um grande número de pessoas ao mesmo tempo, mas o conhecimento é individual. Este consiste na elaboração interior, subjetiva e intersubjetiva da experiência vivida, e funciona como esquema de referência para o sujeito.

"Existem 'versões diferentes do real', e que acabam por ser constitutivas deste, até porque as pessoas agem em função de suas crenças... Essas versões... são exatamente as teorias do senso comum - as Representações Sociais." (Kessler, 1998, p. 18).

Segundo Jodelet (apud Kessler, 1986, p. 16), as representações sociais são "uma forma de conhecimento, socialmente elaborada e partilhada, tendo uma visão prática e concorrendo para a construção de uma realidade comum a um conjunto social." São 
"imagens que condensam um conjunto de significações que nos permitem interpretar o que acontece conosco e dá um sentido ao inesperado" (Jodelet apud Andrade, 1996, p. 33).

A representação, então, se encontra numa relação de simbolização (está no lugar de) e de interpretação (confere significados a). Por outro lado, é uma construção e uma expressão do sujeito, que serve para coordenar a ação sobre o mundo e sobre os outros.

Sendo construção, uma representação "nunca é uma cópia... do mundo lá fora. Representar é substituir um objeto ausente, ou 'reapresentá-lo' - apresentá-lo novamente, com a roupagem das novas significações." (Kessler, 1998, p. 18).

O conhecimento, o afeto e a ação são três facetas da representação que se apresentam imbricadas entre si. O processo de apreensão do significado da situação de aposentado se dá para os idosos também pela representação das atividades cotidianas porque só através deste processo, segundo bvchelovitch (1997, p. 7), o objeto-mundo pode ser obtido. Eeste acesso ao mundo se dá "por via da atividade, desejo, cultura e construção.” (bvchelovitch, 1997, p. 7).

Lane (1989, p. 35), citando Malrieu, coloca que

“... a representação social se constrói no processo de comunicação, no qual o sujeito põe à prova, através de suas ações, o valor - vantagens e desvantagens - do posicionamento dos que se comunicam com ele, objetivando e selecionando seu comportamento e coordenando-o em função de uma procura de personalização. Desta forma, a representação social se estrutura tanto pelos objetivos da ação do sujeito social quanto pelos dados que concordam ou se opõe a eles."

Para Doise (1990, apud Sá, 1996, p. 33),

“... representações sociais são princípios geradores de tomadas de posição ligadas a inserções específicas em um conjunto de relações sociais e que organizam os processos simbólicos que intervém nessas relações." 
A partir destas idéias, se entende que a cada ação do indivíduo em suas relações, novas situações se estabelecem, e o significado e valor a estas atribuído é construído no processo de comunicação com os outros. O sentido individual dado à ação passa, então, pela apreensão que os outros fazem da mesma.

Por sua vez, a apreensão que o idoso e seu grupo social fazem das atividades a que este passou a se dedicar mais recentemente se relaciona com outros conjuntos de representações mais amplos e consolidados, que significam o envelhecimento, o tempo livre, a terceira idade e mesmo o que é próprio do universo masculino ou do feminino no que se refere a estes termos.

Ao re-apresentar as próprias atividades à entrevistadora com um sentido próprio, o idoso busca ainda descrevê-las de forma a ser compreendido, utilizando símbolos culturalmente compartilhados. E a configuração destes símbolos se dá em função do seu habitus, da história e da situação social em que vivem estes idosos. Em todo este processo de ação comunicativa se vão construindo as representações de suas atividades.

"A única possibilidade para que ocorra a coincidência de perspectivas depende do esforço de uns em direção aos outros, de um processo de ação e discurso que contenha tanto as diferenças como as similaridades entre as pessoas, isto é, o diálogo." (bvchelovitch, 1994, p. 68) Para Kessler (1998, p. 26), esta coincidência de perspectivas vem a ser o consenso, essencial para a Representação Social, o que não significa a ausência do contraditório.

"Uma tal concepção consensual não está presente em Moscovici, que não considera o consenso como característica essencial do funcionamento ou do produto das representações sociais... Assim como as inserções e as situações sociais não são jamais completamente idênticas, os múltiplos processos que intervêm nas tomadas de posição que são também variados. Essa dupla fonte de variação pode gerar uma multiplicidade aparente de tomadas de posição que são, entretanto, produzidas por princípios organizadores comuns." (Doise 1990, p. 127 apud Sá, 1996, p. 35) 
As representações de um indivíduo não são independentes. Para Jodelet (1984), são respostas individuais, enquanto manifestações de tendências do grupo de pertença ou de afiliação no qual os indivíduos participam, funcionando como estruturas estruturadas. Mas são também expressão da realidade intra-individual, uma exteriorização do afeto, funcionando como estruturas estruturantes. Relacionam-se a outros sistemas de representação e expressam um discurso sobre a sociedade inteira.

Assim, fica um pouco mais clara a idéia de Moscovici (Andrade, 1996) de que as Representações Sociais correspondem, por um lado, à substância simbólica que participa de sua elaboração e, por outro, à prática que produz esta substância.

Jacques (1995, p. 169) escreve que, ao penetrar no psiquismo, o imaginário social faz uma trama de relacionamentos e articulações, sendo acrescentado de propriedades, transformando e sendo transformado a maneira deste psiquismo, da realidade e da própria vida do indivíduo. Forma-se um sentido pessoal que não exclui a dimensão coletiva: a representação social.

Se tomamos um recorte do discurso de Elaine $^{3}$ ( 62 anos), viúva, enfermeira e professora universitária aposentada por tempo de serviço ao constatar que estava perdendo a visão, podemos buscar compreender como os sistemas de representação citados se combinam na apreensão do sentido de suas atividades atuais.

“... as necessidades aumentam, as frustrações aumentam, se ele não tem algum serviço paralelo, alguma coisa... que $o$ aposentado se sente uma pessoa completamente isolada, porque ele perde... aquela vida social que ele tinha com seus companheiros, com as suas companheiras... Até que uns conseguem se agrupar, então ele tenta... fazer aqueles encontros de pessoas idosas, isso e aquilo. Eu, ainda não participei de nada disso porque até hoje eu não tive condições de participar, condições emocionais, de saúde. Eu não vou dizer que eu não... eu acho que eu preciso procurar sim... Eu tenho que retomar isso aí, e para retomar é lento, devido ao meu estado de saúde."

${ }^{3}$ Todos os nomes empregados são fictícios. 
Para Peixoto (1998 p. 80), “... modificações na legislação brasileira acentuaram a representação social do aposentado, que passa a ser fortemente associada à velhice." A velhice, por sua vez, está ligada à decadência, como se pode identificar no trecho acima, em que aparece esta idéia assumida como verdade enquanto teoria do senso comum ("as necessidades aumentam, as frustrações aumentam...").

O isolamento e a necessidade de ter um "serviço paralelo" aparecem associadas à aposentadoria, chamando atenção para o impacto do desligamento dos relacionamentos estabelecidos no espaço de trabalho e da perda da identidade de trabalhador, bem como uma desvalorização do tempo livre.

Cita-se ainda Peixoto (1998 p. 80) para pensar a representação de terceira idade. Para ela, "a rubrica da terceira idade é fundamentalmente empregada nas proposições relativas à criação de atividades sociais, culturais e esportivas", e a representação de terceira idade se relaciona aos "aposentados dinâmicos" e aos "jovens velhos", saudáveis e ativos. Com isso, a inserção em grupos direcionados a este público se apresenta como possível alternativa à frustração e ao isolamento social, como se pode identificar no trecho de discurso apresentado.

Everaldo (78anos), tipógrafo aposentado por tempo de serviço, viúvo, mas vivendo com a segunda esposa, também passou por um período de frustração, mas se sente vitalizado hoje em dia, freqüentando diversos grupos de convivência.

"Eu larguei. Achei que com sessenta e seis anos eu não precisava mais trabalhar, porque eu tinha sessenta $e$ seis anos. Mas era besteira minha. Ainda dá pra trabalhar. Quando o velho é conservado como eu sempre fui, dava ainda. Mas daí eu caí numa depressão daquelas. Já tava, né, por causa da morte dela."

“... mas peguei aqueles remédios [que tomava para depressão] e coloquei tudo no lixo, sabe, e não tomei nunca mais... É isso que eu digo. Essas reuniões, esses bailezinhos, esses passeios, são uma terapia tremenda." 
Enquanto o entendimento de Elaine do cotidiano atual como composto de poucas atividades tem para ela um significado negativo, ter toda a semana ocupada com a freqüência aos grupos faz com que Everaldo represente suas atividades como uma forma de vitalizar o corpo e a mente, de valor positivo. A idéia de "vitalização da mente" é conteúdo simbólico comum às representações de outros idosos entrevistados.

“... então eu comprei um computador, estou... vendo o que posso aproveitar ainda dos neurônios inativos... talvez virgens, muitos deles." (João, 75 anos, advogado aposentado por tempo de serviço)

"É isso aí, me esforço para preencher as minhas horas para, primeiro, manter meu cérebro ocupado, porque eu acho necessário. É como uma ginástica para manter minha saúde mental." (Heitor, 80 anos, arquiteto aposentado por doença)

Além desta preocupação consigo mesmo, com a própria saúde mental, que aparece na representação das atividades cotidianas, se pode identificar conteúdos relacionados à necessidade de sentimentos de utilidade para outros. O idoso quer manter uma função social, uma responsabilidade. O idoso entende que o próprio tempo livre deve ser ocupado de forma produtiva, como se pode compreender a partir dos seguintes trechos dos depoimentos de entrevistados.

"A gente deve procurar fazer, servir, né, ajudar os necessitados e, ao mesmo, tempo, ocupar o tempo de uma pessoa aposentada." (Júlio, 62 anos, farmacêutico aposentado por tempo de serviço, referindo-se ao seu trabalho voluntário no "leonismo")

"Para ser real, eu não tenho o conhecimento técnico, e quero este conhecimento de como tirar o máximo proveito do computador, seria fazendo um trabalho pessoal ou para os outros e, assim, ter um computador não simplesmente como enfeite dentro de casa..." (Jão, 75 anos)

"Me orgulho de sempre fazer isso, sempre fiz e gosto muito de ajudar e servir." (Ana, 74 anos, funcionária pública aposentada por tempo de serviço) 
Para Moscovici (1978, apud Andrade, 1996 p. 37), cada universo de opinião apresenta as dimensões: atitude, informação e campo de representação ou imagem. A atitude indica se o sujeito é favorável, desfavorável ou neutro perante o objeto de representação, carregando a dimensão valorativa. Sá (1996, p.32) traz em seu texto a seguinte citação de Moscovici no que se refere a esta questão: “... a atitude é a mais freqüente das três dimensões e, talvez, geneticamente a primeira. Por, conseguinte, é razoável concluir que as pessoas se informam e representam alguma coisa socialmente depois de terem tomado uma posição, e em função da posição tornada."

A disciplina, os horários rígidos e a hierarquia, características do mundo do trabalho, que reproduz aspectos fabris nos mais diversos espaços laborativos, são traços da ação sobre o mundo em relação aos quais os aposentados as representações dos aposentados se apresentam como desfavoráveis. Não querem manter estes traços em suas atividades atuais, ainda que trabalhem.

A liberdade de sair de casa a hora que quer é valorizada positivamente na organização das atividades atuais. Ao falar das características consideradas negativas do mundo do trabalho, as denominam "compromisso" e comparam a características da prisão.

“E eu saí de lá e, pelo menos, eu fico mais tranqüilo e faço a vida que gosto. A hora que eu quero sair de casa eu saio, a hora que eu quero ler eu leio, a hora que eu quero ouvir música eu ouço e assim por diante..." (Luís, 73 anos, professor universitário e dentista aposentado por tempo de serviço)

"Agora é curtir os netos e, de vez em quando, dar umas voltinhas. Eu me sinto bem. A hora que eu quero sair, eu saio." (Marta, 63 anos, viúva, comerciária com aposentadoria proporcional)

“Tem alguns que se aposentam e precisam, face à insuficiência de seu ganho, precisam trabalhar... Agora, o nosso caso... em que a gente ganha o suficiente para se manter, ter um padrão de vida, uma qualidade de vida, ainda sobra para a gente fazer o que mais gosta, ou seja, viajar, né. Então eu acho que não há necessidade nenhuma de compromisso ou de preocupação em ganhar mais." 
"Tenho esta farmácia, que eu pretendo, em seguida, dentro de, no máximo, um ano, largar, e ficar com esta atividade de turismo, sem maiores compromissos."

"E eu não queria este compromisso de horário de maneira alguma. Agora, responsável de uma farmácia permite isso, porque não tem horário determinado... isso é importante, não se fica preso." (Júlio, 62 anos, é responsável por uma farmácia)

“Eu não sei se eu vou continuar não. Em parte é porque eu vou ficar meio presa. Exemplo, assim, uma vez por semana eu tenho que ir lá para cuidar dos processos, avaliar, opinar e tudo o mais, e eu não tenho mais necessidade de ficar trancada." (Elaine, GZanos, é membro de uma comissão de ética)

A dimensão das representações que Moscovici denomina de informação diz respeito à organização de conhecimentos que um grupo possui a respeito de um objeto social. Quando se discutiu acima que outros universos representacionais estariam envolvidos nas representações dos aposentados sobre suas atividades atuais, se pôde clarear algo deste aspecto. É interessante refletir ainda, no entanto, sobre a natureza destas informações.

Enquanto se pensa as representações sociais mais freqüentemente como processos de ancoragem e objetivação de conteúdos do reificado produzidos através de uma forma de conhecimento dito científico, os conteúdos representados que apoiam as representações dos aposentados sobre a própria situação são estes mesmos também produzidos no senso comum.

Citando Wagner e Elejabarrieta, Sá (1996 p. 37) mostra uma possível descrição do contexto fenomenal das representações sociais:

"O primeiro é o que caracteriza a perspectiva original dar representações como conhecimento vulgar... de idéias científicas popularizadas. O segundo é o extenso campo dos objetos culturalmente construídos através de uma longa história e seus equivalentes modernos. O terceiro é o campo das condições e acontecimentos sociais e po- 
líticos, onde as representações que prevalecem têm um curto prazo de significação para a vida social. Estes três campos constituem o que podemos denominar de topografia da mente moderna."

A dimensão "campo de representação" remete, segundo Moscovici, à idéia de imagem de modelo social, ao conteúdo concreto e limitado das proposições acerca de um aspecto preciso do objeto de representação.

Ao pensar as atividades que os aposentados desempenham atualmente e avaliá-las globalmente, tomando em consideração o tipo de atividade que sempre foi desempenhado ao longo da vida do sujeito, se percebe que, no dia-a-dia atual, os idosos procuram dar continuidade a hábitos que sempre mantiveran principalmente na vida profissional. Só que este hábito se apresenta hoje sob nova forma, reorganizado de acordo com a realidade da aposentadoria.

Assim, o construtor se dedica hoje à escultura; a funcionária pública que passava o dia a trocar gentilezas com as colegas no espaço de trabalho ainda se reúne com elas uma vez por mês para almoçar, e as mantém como único grupo de relacionamento fora do lar; a professora segue dando aulas na Universidade para a Terceira Idade; o "mateiro" itinerante ainda explora a terra, agora num sítio só.

$\mathrm{E}$ as reflexões a respeito de suas atividades atuais vêm carregadas das idéias sobre a própria finitude, sobre a morte, além das já comentadas idéias de decadência contidas nas representações de velhice.

"Tanto que agora, com 80 anos, estou fazendo uma coisa absurda. Absurda mesmo. Que é mais cômico que outra coisa Estou aprendendo idiomas... E tanto na escola, no grupo que freqüento, bastante encabulado pela idade, eu expliquei que não sabia falar o idioma que se falava no outro mundo, e eu queria chegar preparado lá, pois não há outra necessidade." (Hugo, 80 anos)

"É, passou dos 60, já sabe... sempre fiz serviço pesado. E eu sou muito estúpido pro serviço assim. Mas... eu 
não posso me queixar. Eu também já estou velho. Durando mais um ou dois anos já está bom... Ah, se eu não tiver o que fazer, tu acha que eu vou ficar parado assim?... A gente parou, a doença..." (Carlos, 80 anos, agricultor aposentado por doença)

Ecléa Bosi (1994 p. 44), em seu estudo sobre lembranças de velhos, traz à baila as idéias de Bergson que, analisando a própria experiência de percepção, coloca que cada imagem que percebe em si está mediada pela imagem de seu próprio corpo. Assim, “o sentimento confuso da própria corporeidade é constante e convive, na vida psicológica, com a percepção do meio físico e social que circunda o sujeito". Bergson, de acordo com Bosi, observa ainda que este "presente contínuo se manifesta, na maioria das vezes, por movimentos que definem ações e reações do corpo sobre seu ambiente", estando estabelecido o nexo entre imagem do corpo e ação.

Nas representações dos entrevistados sobre suas atividades atuais, a imagem do corpo está freqüentemente presente. Seja quando Hugo fala na ginástica para manter a saúde mental, ocupando o cérebro, ou quando Jaão diz querer ver se ainda existem neurônios inativos, seja quando outras partes do corpo são utilizadas como imagem significada na representação.

O corpo como representante significado nas práticas atuais pode aparecer até em situações um tanto patológicas, como no caso de Luzia (74 anos):

"Então eu dizia assim: depois que eu me aposentar, eu vou dar um descanso para as minhas pernas, e isso foi a pior coisa que eu fiz... porque eu fiquei parada dentro de casa, e hoje estou com minhas pernas meio entrevadas... não gosto de andar na rua, tenho até medo de andar sozinha."

Mas a parte do corpo cuja imagem mais aparece nas representações dos idosos de sua ação sobre o mundo é a mão. Mesmo Bosi (1994 p. 468), ao falar na "memória do trabalho" dos sujeitos 
que entrevistou, se utiliza do poema "Os trabalhos da mão", de Alfredo Bosi, valorizando esta imagem. A mão executa, mas a falha da mão também é apontada como motivo para a ausência de atividades laborativas, que sempre precisa de justificativa.

"Tu acha que eu fico devalde? Só quando eu não posso trabalhar. Hoje eu amanheci com a mão inchada, me doendo assim." (Leoni, 73 anos, empregada doméstica aposentada por tempo de serviço)

"Só para a minha casa e só a minha roupa. Que o filho lava as dele... porque eu não posso mais esfregar essas calças grossas, esses brim-coringa... eu não tenho mais força nas mãos." (América, 80 anos, lavadeira aposentada por doença)

Destacaram-se como conteúdos das representações dos aposentados sobre suas atuais atividades as seguintes idéias: forma de sentir-se útil, forma de vitalizar o corpo e a mente e forma de dar continuidade a hábitos adquiridos ao longo da vida de trabalho, que foram caracterizadas como "compromisso" (desvalorizado e tido como desnecessário nesta etapa da vida) ou "sem compromisso" (valorizado positivamente).

Importa observar que estas formas de apresentar a própria ação são formas peculiares das caracterizações das atividades laborativas, pouco presentes no cotidiano atual dos aposentados.

Conclui-se que características de atividades de trabalho são mantidas e valorizadas positivamente pelos idosos ao dimensionarem suas práticas cotidianas. Por outro lado, a disciplina e a hierarquia são características do mundo do trabalho às quais os aposentados são avessos, não considerando importante mantêlas nessa etapa da vida, o que aparece em sua compreensão das atividades que realizam atualmente. Essas representações de sua ação combinam com a idéia de que o aposentado evita sentir-se totalmente desligado do trabalho, mantendo referenciais identitários e evitando uma brusca ruptura no que até a aposentadoria lhe possibilitava um reconhecimento de si. 


\section{Referências bibliográficas}

1 ANDRADE, Oseias Guimarães. Cuidado ao Idoso com Seqü ela de Acidente Vascular cerebral: representações do cuidador familiar. Ribeirão Preto, USP, 1996

2 BOSI, Ecléa. Memória e Sociedade: lembranças de Velhos. São Paulo, T. A. Queiroz/EDUSP, 1987.

3 JACQUES, Maria da Graça. Saúde Mental e Trabalho: a construção da identidade do trabalhador, Cadernos de Sociologia, Porto Alegre, v. 7, p. $167-$ 175, 1995.

4 KESSLER, Adriana Silveira. Capitalismo Versus Socialismo: a representação social da sociedade alternativa. Porto Alegre, PUCRS, 1998

5 LANE, Sílvia T. M. Linguagem, Pensamento e Representações Sociais. In: CODO, Wanderley; LANE, Sílvia T. M. (Orgs.) Psicologia Social: o homem em movimento. 7ed., São Paulo, Brasiliense, 1989.

6 PEIXOTO, Clarice. Entre o Estigma e a Compaixão e os Termos Classificatórios: velho, velhote, idoso, terceira idade. In: BARROS, M. M. L. de. Velhice, Terceira Idade? Rio de Janeiro, Ed. Fundação Getúlio Vargas, 1996

7 SÁ, Celso Pereira de. Núcleo Central das Representações Sociais. Petrópolis, Vozes, 1996 